\title{
Fortalecimiento institucional en materia de refugiados ambientales en México*
}

\author{
María Teresa Montalvo Romero** \\ Ana Paola Román Hernández ${ }^{* * *}$
}

RESUMEN: En la primera década del siglo $X X I$, el fenómeno del cambio climático ha ocasionado una serie de desastres naturales, que han puesto en entredicho, la actuación de las instituciones gubernamentales en materia de protección a los refugiados ambientales y la violación de un derecho humano básico: el derecho a un medio ambiente sano.

El presente artículo tiene por objetivo presentar un análisis sobre la importancia de Instituciones gubernamentales y su relación con la calidad institucional, para lo cual está estructurado en tres partes, la primera desarrolla el concepto y la importancia del enfoque institucional, la segunda aborda el marco institucional en torno a la temática de refugiados ambientales y la tercera evalúa la importancia de fortalecer las instituciones gubernamentales para enfrentar esta problemática a través de la acción colectiva. Palabras clave: cambio climático, refugiados ambientales, marco jurídico, instituciones gubernamentales, acción colectiva.
ABSTRACT: In the first decade of the 21st century, the phenomenon of climate change has caused a series of natural disasters, which have called into question the actions of government institutions in terms of protecting environmental refugees and the violation of a basic human right: the right to a healthy enviroment.

This article aims to present an analysis on the importance of institutions and the relationship with government organization, for which it is structured in three parts, the first develops the concept and the importance of the institutional approach, the second deals with the institutional framework in around the issue of environmental refugees and the third evaluates the importance of strengthening government institutions in Mexico to address this problem through collective action.

Keywords: climate change, environmental refugees, legal framework, governmental institutions, institutional quality.

\footnotetext{
* Artículo recibido el 5 de octubre de 2019 y aceptado para su publicación el 12 de marzo de 2020.

** Doctora en Derecho Público, Docente de la Facultad de Ciencias Administrativas y Sociales de la Universidad Veracruzana, Docente con perfil Prodep.

*** Estudiante del Programa de Doctorado en Ciencias Administrativas y Gestión para el Desarrollo de la Universidad Veracruzana.
} 
SUMARIO: Introducción. 1. ¿Qué entendemos por Institución? 1.1. Marco teórico. 2. Conceptualización de refugiados ambientales. 2.1. Marco institucional en México. 3. Experiencia internacional: Suecia y Finlandia. 3.1. La acción colectiva impulsor del fortalecimiento institucional. Conclusiones. Fuentes de consulta.

\section{Introducción}

Es un hecho, que las instituciones han jugado un rol fundamental dentro las sociedades, al constituirse como un elemento clave para el desarrollo de los Estados, contar con buenas instituciones mejora el nivel de vida de sus ciudadanos.

En ese sentido, se hace necesario establecer el entorno institucional formal que existe en México, en relación con el marco legal y administrativo que rodea al tema de los refugiados ambientales para poder relacionar cuáles son las reglas del juego formales e informales que se desarrollan a partir de este fenómeno, reconociendo que hasta el día de hoy el refugiado ambiental no es una figura legalmente establecida.

El objetivo del artículo es presentar un análisis documental, a partir de la teoría neo institucional que nos permita identificar la necesidad en México de incluir en la agenda pública a los refugiados ambientales en los planes y programas nacionales, lo que permitirá desarrollar una capacidad de respuesta acorde a los nuevos riesgos globales.

\section{1. ¿Qué entendemos por Institución?}

Para el estudio de las instituciones, sin duda, es fundamental partir de una noción de Institución, para poder abordar la problemática desde este enfoque. Es así que, para ello nos basaremos en la definición propuesta por North (2014:13) quien refiere a las instituciones, como "las reglas del juego en una sociedad, o más formalmente, son las limitaciones ideadas por el hombre que dan forma a la interacción humana. Por consiguiente, estructuran incentivos en el intercambio humano, sea político, social o económico".

Al respecto de las limitaciones, el autor plantea que, pueden ser formales e informales. Las formales se pueden entender como normas ideadas por el ser humano y las informales como acuerdos y códigos de conducta.

Ahora bien, con relación a las instituciones o limitaciones formales éstas se relacionan con diversas reglas políticas, judiciales y económicas, que pueden ser generales o específicas, que facilitan el intercambio político o económico, mismas que se convierten en las reglas del juego con base en las cuales los diferentes actores están interactuando y que determinan la forma en que se desarrollará el juego (2014:67).

Por otro lado, a las instituciones informales siguiendo a Boyd y Richerson, North, refiere que están relacionadas con la cultura, entendida como la "transmisión de una generación a la siguiente, por la enseñanza y la imitación, de conocimientos, valores y otros factores que influyen en la conducta" (2014:55).

En virtud de lo anterior, coincidimos con el autor al identificar que los agentes que participan en cualquier organización de refugiados estarán limitados por instituciones formales e informales. Bajo ese esquema, las formales se verán reflejadas principalmente 
en el marco regulatorio que le da sentido legal a la organización, con relación a los otros organismos o agencias gubernamentales con las cuales interactúa. Por su parte, las informales se relacionan con la cultura que impera en una sociedad determinada, en este caso el interés se centra en la cultura política, como una forma de anteponer el interés político de los actores del gobierno a la eficiencia de los organismos gubernamentales encargados de la atención de los refugiados.

\section{1. Marco teórico}

Dentro de la temática de refugiados ambientales, sin duda el neo institucionalismo brinda una serie de elementos a considerar dentro de la problemática, ya que permite establecer el nivel de institucionalización de las estructuras formales en México.

En este orden de ideas, es que se relacionan las teorías del neo institucionalismo y el isomorfismo institucional, ${ }^{1}$ toda vez que el propósito clave del análisis institucional no es exponer la ineficiencia de las prácticas institucionales ni celebrar la no optimización de los acuerdos institucionales. Powell y Dimaggio argumentan que, "el punto no es discernir si las instituciones son eficientes, sino llegar a explicaciones sólidas de cómo las instituciones incorporan las experiencias históricas en sus reglas y lógicas organizativas" (1999:75).

En este sentido, nos parece interesante retomar el planteamiento que realiza la Organización para la Cooperación y el Desarrollo Económicos (OCDE), CEPAL (Comisión Económica para América Latina y el Caribe) y el Banco de Desarrollo de América Latina (CAF), en el Informe Perspectivas económicas de América Latina, en el sentido de que "es necesario reconectar a las instituciones con los ciudadanos, respondiendo de mejor manera a sus demandas y aspiraciones, para fortalecer un modelo de crecimiento inclusivo y sostenible en América Latina y el Caribe. La región debe avanzar hacia instituciones más confiables, más capaces, más abiertas e innovadoras para continuar con una senda de mayor desarrollo inclusivo" (OCDE, CAF y CEPAL, 2018).

No se trata de crear nuevas instituciones sino de fortalecer las existentes, es decir, el Instituto Nacional de Migración(INAMI) y la Comisión Mexicana de Ayuda para Refugiados (COMAR) donde se ponga especial énfasis en instituciones especializadas en función del objetivo, que para el caso que nos ocupa sería el de contar con unidades de atención para refugiados ambientales como mecanismos preventivos no reactivos, para evitar la duplicidad de funciones, costos económicos y riesgos de conflictos institucionales.

Lo cual nos parece muy viable toda vez que, a partir de febrero de 2019, la Comisión Mexicana para Refugiados y el Instituto Nacional de Migración por primera vez establecen una relación interinstitucional, en vías de garantizar la asistencia institucional para las personas que requieran asilo en nuestro país, con base en una política migratoria basada en el respeto de los Derechos Humanos. Lo cual obedece a las constantes caravanas de

\footnotetext{
${ }^{1}$ Powell y DiMaggio plantean el concepto de isomorfismo, y lo definen como "un proceso limitador que obliga a una unidad en una población a parecerse a otras unidades que enfrentan las mismas condiciones ambientales". El isomorfismo institucional es, pues, un concepto que explica el proceso a través del cual las organizaciones se vuelven más homogéneas unas con respecto a otras al enfrentar condiciones contextuales aparentemente similares
} 
migrantes centroamericanos que han llegado a nuestro país en los últimos meses que obliga al Estado a tomar medidas al respecto, siendo medidas reactivas más que preventivas.

Finalmente, queda claro que las organizaciones gubernamentales nacen predeterminadas en sus fines, su estructura y sus formas de funcionamiento, tienen su contexto particular, generan su propia lógica de acción, sus actores se desarrollan en esquemas de interacción, con una especificidad propia y que ante la aparición de nuevos esquemas organizacionales hay una redefinición del rol que juega el Estado que tiene que adaptarse a diseñar sistemas de planeación menos rígidos y necesariamente participativos; donde el rumbo y acciones del plan serán acordados conjuntamente con la participación de todos los miembros de la organización.

\section{Conceptualización de refugiados ambientales}

Es un hecho que, a partir del fin de la Segunda Guerra Mundial, el desarrollo comienza a concebirse como crecimiento económico, orientándose hacia el logro de un acelerado desarrollo industrial y tecnológico; a este paradigma se le llamó "modelo de desarrollo", mismo que ha acarreado negativas consecuencias para la humanidad- señaladas por la escuela latinoamericana- relacionadas con el incremento del deterioro de las condiciones ambientales del planeta y los diferentes sistemas biofísicos y sociales que lo constituyen; lo cual ha desencadenado la llamada crisis ambiental. En ese contexto, Escobar sostiene que: basta una mirada superficial a los paisajes biofísicos, económicos y culturales de la mayor parte del Tercer Mundo para darse cuenta de que el desarrollo está en crisis, y que la violencia, pobreza y deterioro social y ambiental crecientes son el resultado de cincuenta años de recetas de crecimiento económico, ajustes estructurales, macroproyectos sin evaluación de impacto, endeudamiento perpetuo, y marginamiento de la mayoría de la población de los procesos de pensamiento y decisión sobre la práctica social (2007:11)

Como resultado de esta crisis ambiental, derivada del uso indiscriminado de recursos que acompaña al modelo de desarrollo basado preponderantemente en el interés por el crecimiento económico, surge un fenómeno denominado cambio climático, ${ }^{2}$ que ha ocasionado una serie de desastres naturales que van desde incendios forestales hasta tsunamis, $y$, por ende, refugiados ambientales.

Felipe (2018: 8) menciona que "las migraciones climáticas son un fenómeno complejo, heterogéneo y multicausal, que comprende situaciones tan diferentes como las de las comunidades que ante una fuerte sequía ven sus cultivos peligrar y envían a un miembro de la familia a trabajar a un pueblo cercano para aumentar sus ingresos económicos, como las de los habitantes de los pequeños Estados insulares de escasa elevación, que presencian el avance del mar en sus territorios y sus consecuencias (salinización de los acuíferos, pérdida de cultivos, etc.)

\footnotetext{
2 Entendido como un "cambio de clima atribuido directa o indirectamente a la actividad humana que altera la composición de la atmósfera global y que se suma a la variabilidad natural del clima observada durante períodos de tiempo comparables" (Artículo 1 de la Convención Marco de las Naciones Unidad sobre el Cambio climático).
} 
Lo anterior, nos brinda un panorama general sobre la importancia de visualizar cómo, a partir de la adopción del modelo de crecimiento económico, durante décadas se fue relegando el tema del medio ambiente, lo que implicó un crecimiento económico a costa de la invasión a los recursos naturales y por ende una crisis ecológica, porque los modelos actuales de gestión de recursos se vieron rebasados por los desafíos que planteaba el hecho que los recursos no son infinitos y que el hombre no controla el medio ambiente. De ahí que Hildyard refiere lo siguiente:

En todo el mundo, cientos de miles de personas se ven forzadas a abandonar sus hogares para dejar sitio a las minas, campos petrolíferos y de gas, oleoductos, centrales eléctricas y refinerías que proporcionan la energía que la economía mundializada necesita. Algunos son desposeídos porque sus tierras son directamente ocupadas por las infraestructuras para la producción energética; otros los son debido a que la contaminación resultante arruina sus tierras e imposibilita la subsistencia; otros más, como es el caso de Marta, se convierten en víctimas de intimidaciones y hostigamientos por intentar defender los derechos de los afectados. A todos ellos hay que sumarles las innumerables personas que acaban sin hogar debido a los impactos climáticos provocados por el consumo de los combustibles que se han extraído, o por los conflictos generados por esas actividades extractivas (2007: 37).

El término refugiado ambiental surge por vez primera en el Informe del Programa de Naciones Unidas para el Medio Ambiente, donde El-Hinnawi refiere lo siguiente:

son individuos que se han visto obligados a dejar su hábitat tradicional de forma temporal o permanente, debido a un marcado trastorno ambiental, ya sea a causa de peligros naturales $\mathrm{y} / \mathrm{o}$ provocados por la actividad humana, como accidentes industriales que han provocado su desplazamiento permanente por grandes proyectos económicos de desarrollo, o que se han visto obligados a emigrar por el mal procesamiento y depósito de residuos tóxicos, poniendo en peligro su existencia o afectando su calidad de vida(1985:4) .

Por otro lado, de acuerdo con el Alto Comisionado de la Organización de las Naciones Unidas para los Refugiados (ACNUR), los refugiados ambientales son definidos como: "personas desplazadas en su propio país o que se han desplazado a través de fronteras internacionales debido a la degradación, el deterioro o la destrucción del medio ambiente."(1993:2).

Actualmente, existen instrumentos internacionales que brindan protección a los migrantes, no obstante, los motivos ambientales no son considerados como una razón suficiente, por la que las personas sean perseguidas o forzadas a huir. Es por ello, que los refugiados ambientales se encuentran en una laguna jurídica, que no hace más que evidente la falta de protección hacia su persona y por tanto una violación a un derecho humano básico: el derecho a un medio ambiente sano.

En ese sentido, es imperativo buscar los mecanismos jurídicos y de participación social, que den respuestas eficaces para una asistencia integral a dichos individuos, y no sólo de manera interna sino también como receptores de refugiados ambientales.

El gran desafío que representa esta temática involucra la colaboración de diversos actores públicos, gubernamentales, sociales y académicos con el fin de avanzar en la búsqueda e implementación de soluciones en lo que corresponde tanto a la normatividad, como a su implementación. 
A nivel internacional, se reconoce que hay una serie de instrumentos que dan origen a la adopción de medidas que los Estados utilizan como mecanismos de cooperación para garantizar el derecho de las personas a una migración ordenada. A continuación, se presentan los principales instrumentos de cooperación en materia de migración.

Tabla 1. Instrumentos de cooperación internacional entre los Estados en materia de migración.

\section{INSTRUMENTO}

Pacto Mundial para una Migración segura, ordenada y regular. (ONU 2018)

Programa de Migración, Medio Ambiente y Cambio Climático: Evidencia para la Política. (MECLEP,2016)

Iniciativa Nansen (2016)

Global Compact on Migration

Agenda 2030

\section{DESCRIPCIÓN}

Adopción formal del Pacto Mundial sobre Migración, acordado por los Estados Miembros de la ONU. Basado en "los valores de la soberanía del Estado, la responsabilidad compartida, la no discriminación y los derechos humanos y reconoce que se requiere de un enfoque cooperativo para optimizar los beneficios generales de la migración" (ONU, 2018)

Programa multilateral, financiado por le Unión Europea, tiene por objetivo "contribuir a la base mundial de conocimientos sobre la relación entre la migración y el cambio del medio ambiente, incluido el cambio climático. La investigación innovadora de MECLEP tiene como objetivo formular opciones de política sobre cómo la migración puede beneficiar a las estrategias de adaptación a los cambios ambientales y climáticos" (MECLEP, 2016, párrafo 1).

Iniciativa donde participaron: Australia, Bangladesh, Costa Rica, Alemania, México, Filipinas y Kenia en su grupo de dirección y culminó con la adopción de la Agenda de Protección y el establecimiento de la Plataforma de Desplazamiento por Desastres, cuyo objetivo fue convertirse en un foro de diálogo e intercambio de información, así como de desarrollo de políticas y normativas, por medio de la colaboración entre políticos, especialistas e investigadores. (ACNUR, 2016).

El Pacto Mundial se enmarca en armonía con el objetivo 10.7 del Programa de Desarrollo Sostenible de 2030 en el que los Estados Miembros se comprometen a cooperar internacionalmente para facilitar una migración segura, ordenada y regular y su alcance se define en el Anexo II de la Declaración de Nueva York.

La Agenda 2030 para el Desarrollo Sostenible, adoptada en la Cumbre de la ONU el 25 de septiembre de 2016 en seguimiento a las metas establecidas en los Objetivos de Desarrollo del Milenio y los acuerdos previos, establece un programa de transformación en el que las personas migrantes están reconocidas como actores y sujetos 


\begin{tabular}{|c|c|}
\hline & $\begin{array}{l}\text { del desarrollo humano y económico sostenible en } \\
\text { diversos aspectos económicos, sociales y } \\
\text { ambientales. }\end{array}$ \\
\hline Foro Mundial sobre Migración y Desarrollo (FMMD) & $\begin{array}{l}\text { Es un proceso de consultas de carácter informal en } \\
\text { el que participan de manera voluntaria los países } \\
\text { miembros de las Naciones Unidas. El Foro surgió a } \\
\text { raíz de una propuesta del Secretario General de la } \\
\text { ONU y tomó como punto de partida las conclusiones } \\
\text { del Diálogo de Alto Nivel sobre Migración y } \\
\text { Desarrollo de } 2006 \text {. El Foro está compuesto por } \\
\text { reuniones de los representantes gubernamentales } \\
\text { además de la reunión de las organizaciones de la } \\
\text { sociedad civil. }\end{array}$ \\
\hline Iniciativa de Berna (2001) & $\begin{array}{l}\text { Proceso de consultas y análisis sobre las migraciones } \\
\text { internacionales que se desarrolló a partir del } \\
\text { Simposio Internacional sobre Migración llevado a } \\
\text { cabo en } 2001 \text { en el que participaron, a invitación del } \\
\text { gobierno de Suiza, expertos en la materia tanto de } \\
\text { organismos internacionales como de la academia y } \\
\text { la sociedad civil provenientes de las diferentes } \\
\text { regiones del mundo. }\end{array}$ \\
\hline
\end{tabular}

Fuente: Con información del Instituto de Estudios y Divulgación sobre Migración (INEDIM), A.C., 2018. Disponible en https://www.estudiosdemigracion.org/foros-y-debates-internacional/.

De esta manera, se evidencia que las Instituciones han realizado esfuerzos por establecer una serie de medidas en temas migratorios, elevando el tema a la atención de la principal instancia de Naciones Unidas sobre refugiados. No obstante, aún no se ven cristalizados en un marco normativo que obligue a los Estados a reconocer la figura de refugiado ambiental en sus leyes migratorias, tanto a nivel internacional como nacional.

\subsection{Marco institucional en México}

Para el caso de los refugiados ambientales, México, a nivel internacional, está suscrito al Estatuto Jurídico Internacional de los Refugiados, regulado en la Convención de Ginebra sobre el Estatuto de los Refugiados de 28 de julio de 1951, con su Protocolo de Nueva York, de 31 de enero de 1967, en cuyo artículo 1.a).2, define al refugiado como:

aquella persona que, debido a fundados temores de ser perseguida por motivos de raza, religión, nacionalidad, pertenencia a un determinado grupo social u opiniones políticas, se encuentre fuera del país de su nacionalidad y hallándose, a consecuencia de tales acontecimientos, fuera del país donde antes tuviera su residencia habitual, no pueda o, a causa de dichos temores, no quiera regresar a él.

Bajo ese orden de ideas, podemos determinar que este instrumento no va acorde con la realidad actual, puesto que las características y la procedencia de los refugiados han cambiad o considerablemente, excluyendo una gran cantidad de variables que inciden en la migración forzada, siendo una de estas la migración motivada por razones medioambientales.

A nivel nacional, con base en la Ley Orgánica de la Administración Pública Federal, la responsabilidad de atender el fenómeno de la migración recae a nivel interno, en la 
Secretaría de Gobernación (SEGOB) a través del Instituto Nacional de Migración (INAMI) y a nivel externo en la Secretaría de Relaciones Exteriores (SRE). Para fines de este artículo, nos enfocaremos en la actuación del INAMI y la Comisión Mexicana de Ayuda a los Refugiados (COMAR).

El Instituto Nacional de Migración fue creado por Decreto presidencial el 19 de octubre de 1993. Con base en el art. 2 de dicho decreto, tiene "por objeto la planeación, ejecución, control, supervisión y evaluación de los servicios migratorios, así como el ejercicio de la coordinación con las diversas dependencias de la Administración Pública Federal, que concurren a la atención y solución de los asuntos regulados con la materia". A partir de 2011, se reforma su marco normativo creándose la Ley de Migración y su Reglamento en 2012.

Para el caso de los refugiados, la institución encargada de proporcionarles asistencia institucional es la Comisión Mexicana de Ayuda a los Refugiados (COMAR), la cual fue creada en 1984, por decreto presidencial, por la necesidad imperante de proteger a guatemaltecos que llegaron a México en grandes números, a solicitar asilo.

Como parte de sus actividades de asistencia, la COMAR realiza un acompañamiento del refugiado, identificando sus necesidades y elaborando un plan de atención a seguir, para poder canalizarlo a las dependencias o instituciones que se requieran para atender las necesidades individuales de cada refugiado.

Los refugiados deben acudir directamente ante las dependencias o instituciones, a realizar los trámites necesarios para recibir los apoyos o servicios que requieren. Si la persona presenta alguna dificultad, al realizar trámites o acceder a servicios, derivada de su condición de refugiado, la COMAR puede intervenir con la finalidad de orientarlo y apoyarlo. Sin embargo, esta institución se encuentra en una transformación institucional derivada de las caravanas de migrantes centroamericanos que han llegado a nuestro país en los últimos meses. Con base en datos de la COMAR, se incrementó el número de solicitantes de asilo de 1,296 en 2013 a 29,600 en 2018.

México cuenta con una serie de instrumentos jurídicos que regulan la actuación de la COMAR, entre los que se pueden mencionar los siguientes: Constitución Política Mexicana de los Estados Unidos Mexicanos (CPEUM), Convención sobre el Estatuto de los Refugiados, Convención Americana sobre Derechos Humanos, Protocolo sobre el Estatuto de los Refugiados, Pacto Internacional de Derechos Económicos, Sociales y Culturales, Pacto Internacional de Derechos Civiles y Políticos, Ley sobre refugiados, protección complementaria y asilo político y la Ley de Migración.

Para el caso de los refugiados, la Ley sobre refugiados, protección complementaria y asilo político publicado el 27 de enero de 2011, en el Diario Oficial de la Federación, que establece en su artículo 13, quienes son considerados refugiados:

La condición de refugiado se reconocerá a todo extranjero que se encuentre en territorio nacional, bajo alguno de los siguientes supuestos:

I. Que debido a fundados temores de ser perseguido por motivos de raza, religión, nacionalidad, género, pertenencia a determinado grupo social u opiniones políticas, se encuentre fuera del país de su nacionalidad y no pueda $\mathrm{o}$, a causa de dichos temores, no quiera acogerse a la protección de tal país; o que, careciendo de nacionalidad y hallándose, a consecuencia de tales acontecimientos, fuera del 
país donde antes tuviera residencia habitual, no pueda o, a causa de dichos temores, no quiera regresar a él;

II. Que ha huido de su país de origen, porque su vida, seguridad o libertad han sido amenazadas por violencia generalizada, agresión extranjera, conflictos internos, violación masiva de los derechos humanos $u$ otras circunstancias que hayan perturbado gravemente el orden público, y

III. Que debido a circunstancias que hayan surgido en su país de origen o como resultado de actividades realizadas, durante su estancia en territorio nacional, tenga fundados temores de ser perseguido por motivos de raza, religión, nacionalidad, género, pertenencia a determinado grupo social u opiniones políticas, o su vida, seguridad o libertad pudieran ser amenazadas por violencia generalizada, agresión extranjera, conflictos internos, violación masiva de los derechos humanos u otras circunstancias que hayan perturbado gravemente el orden público.

En concordancia con esta ley, la Ley de migración reconoce en su artículo 3 fracción XXII, como Refugiado: "a todo extranjero que se encuentre en territorio nacional y que sea reconocido como refugiado por parte de las autoridades competentes, conforme a los tratados y convenios internacionales de que es parte el Estado Mexicano y a la legislación vigente".

Asimismo, el Reglamento de la ley sobre refugiados y protección complementaria publicado en el Diario Oficial de la Federación el 21 de febrero de 2012, establece en sus artículos 4,5 y 6 que se debe entender por temores fundados en cada uno de los supuestos citados anteriormente.

Con base en esta definición, se puede observar que no se contempla en la legislación nacional el concepto de refugiado ambiental ni en la Ley de migración, ni en la Ley sobre refugiados, protección complementaria y asilo político. Lo que nos da una idea de que el marco institucional en México no ha sido desarrollado ampliamente, ya que no está preparado para hacer frente a estos asuntos que comprometen la seguridad humana.

\section{Experiencia internacional: Suecia y Finlandia}

No existe un consenso a nivel internacional, en lo referente a desarrollar un marco institucional que regule el marco normativo para garantizar la protección de los refugiados ambientales. Sin embargo, destaca la experiencia de Suecia y Finlandia al adoptar en sus marcos normativos nacionales la incorporación de mecanismos de protección y tratamiento de esta población, al clasificarlos como "personas en necesidad de protección", y estableciendo de manera escrita mecanismos de protección a esta población en los marcos legales de sus sistemas migratorios. Tal como se muestra en la siguiente tabla:

Tabla 2. Países que contemplan en legislación nacional a los refugiados ambientales.

\begin{tabular}{|l|l|l|l|}
\hline PAÍS & INSTRUMENTO & AÑO & CONTENIDO \\
\hline Suecia & Ley de Extranjería & 2005 & $\begin{array}{l}\text { Sección 2.a categoriza a las personas } \\
\text { en necesidad de protección, a todo } \\
\text { aquel que "es incapaz de regresar a su } \\
\text { país de origen por razón de un desastre } \\
\text { ambiental" (Parlamento Sueco, 2005, } \\
\text { sección 2). Así mismo, "lo } \\
\text { correspondiente se aplica a } \\
\text { extranjeros apátridas que se }\end{array}$ \\
& & &
\end{tabular}




\begin{tabular}{|c|c|c|c|}
\hline & & & $\begin{array}{l}\text { encuentran fuera del país en el que } \\
\text { han tenido previamente su residencia } \\
\text { habitual" (Parlamento Sueco, 2005, } \\
\text { sección 2). La ley de extranjería sueca } \\
\text { en su Sección } 5 \text { concede permisos de } \\
\text { residencia a personas en necesidad de } \\
\text { protección bajo los estándares de su } \\
\text { Sección 2, literales } 1,2 \text { y } 3 \text {. }\end{array}$ \\
\hline Finlandia & Ley de Extranjería & 2004 & $\begin{array}{l}\text { Establece mecanismos de protección } \\
\text { temporal, por un máximo de } 3 \text { años a } \\
\text { personas que "necesitan protección } \\
\text { internacional y que no pueden } \\
\text { regresar con seguridad a su país de } \\
\text { origen o país de residencia } \\
\text { permanente, porque se ha producido } \\
\text { un desplazamiento masivo de } \\
\text { personas en el país o sus áreas vecinas } \\
\text { como resultado de un conflicto } \\
\text { armado, alguna otra situación de } \\
\text { violencia o un desastre ambiental" } \\
\text { (Ministerio del Interior, 2004, pág. 39) }\end{array}$ \\
\hline
\end{tabular}

Fuente: Elaboración propia con base en Ley de extranjería sueca, 2005, disponible en http://cort.as/-F0Ge y Ley de extranjería $\quad$ Finlandia, $2004 \quad$ disponible en http://www.finlex.fi/en/laki/kaannokset/2004/en20040301.pdf

Como podemos observar en la tabla, Finlandia y Suecia aseguran, por lo menos en la ley, que las personas que lleguen por cuestiones de desastres ambientales puedan tener garantía de derechos y un estatus legal que los proteja. Dichas medidas son temporales ya que responden principalmente a fenómenos súbitos que obligan a las personas a migrar, habiendo la posibilidad de que puedan, progresivamente, regresar a su territorio de origen una vez las condiciones ambientales se normalicen.

El hecho de que dichos Estados, asuman voluntariamente la responsabilidad de proteger legalmente a los refugiados ambientales, más allá de la Convención de Ginebra, refleja que estas acciones legales se convierten en una estrategia de gestión por parte de estos países para mitigar las consecuencias económicas y sociales que conllevaría el no contar con mecanismos de prevención para un fenómeno que, según las previsiones científicas se irá acentuando en el futuro.

\subsection{La acción colectiva impulsor del fortalecimiento institucional}

A lo largo del artículo se ha dejado claro que el cambio climático representa un gran desafío para la comunidad internacional debido a las graves amenazas que conlleva, de ahí la necesidad de promover estrategias y mecanismos para enfrentar la problemática de los refugiados ambientales.

De esta manera, los países se comprometen bajo el Acuerdo de París de 2015 y la Agenda 2030 de Desarrollo Sostenible, a estrechar los lazos de cooperación para lograr el desarrollo 
sostenible que involucre las esferas económica, social y ambiental para poder hablar de un modelo de desarrollo sostenible.

Es por ello, que la acción colectiva se convierte en una guía para que el Estado ( a través de sus instituciones), las empresas y la sociedad trabajen de forma coordinada para asumir la responsabilidad de diseñar políticas públicas en aras de proteger a esta población desplazada por cuestiones ambientales.

En Sudamérica, por ejemplo, ya se empieza a desarrollar un entramado de la acción colectiva, Pires (2016:56) sostiene que:

El desarrollo de una estrategia regional en materia de migraciones en el contexto de desastres y cambio climático pasa por la adopción de documentos de referencia, por ejemplo: el Marco de Acción de Sendai y su Agenda 2015-2030 para la reducción del riesgo de desastres; la Agenda Nansen/Plataforma sobre Desplazamientos por Desastres (2015- 2016) para la protección de las personas desplazadas a través de fronteras en el contexto de desastres, que hace recomendaciones sobre la prevención y la gestión de estos desplazamientos, identifica prácticas e instrumentos para la protección de los desplazados y mecanismos para la cooperación entre Estados de la misma región; los Objetivos de Desarrollo Sostenible y la Agenda 2030 para el Desarrollo Sostenible (PNUD, 2015), que establecen metas y recomendaciones en materia de reducción de riesgo de desastres, cambio climático y migraciones; la Cumbre Humanitaria Mundial (2016), que propone una Agenda 2030 para la humanidad integrando la respuesta a desastres y cambio climático y a los desplazamientos que provocan; el Acuerdo de París (UNFCCC, 2015) adoptado durante la COP21, que incorpora los desplazamientos provocados por el cambio climático en norma vinculante.

Otra cuestión a resaltar de la experiencia en la región latinoamericana es el gran reto que han asumido por establecer un marco de cooperación entre la región, al respecto Yamamoto (2019:428) argumenta que la gran diversidad de fenómenos ambientales que se han suscitado en Perú, Argentina y Bolivia han obligado a adoptar medidas legales para mitigar la problemática.

Para el caso mexicano, aún no se logra establecer en la agenda pública la temática de los refugiados ambientales. No obstante, se reconoce que en materia de lucha contra cambio climático, México fue el primer país en Latinoamérica en crear una Ley General de Cambio Climático, publicada en el Diario Oficial de la Federación el seis de junio de 2012, y que dentro de sus objetivos establece: garantizar el derecho a un medio ambiente sano, transitar hacia una economía competitiva, sustentable y de bajas emisiones de carbono, Reducir la vulnerabilidad de la población y los ecosistemas frente a los efectos adversos del cambio climático y garantizar la coordinación y transversalidad entre órdenes de gobierno y dependencias de la Administración Pública Federal, con transparencia y participación corresponsable de la sociedad.

Además de que nuestro país ha enfatizado la importancia de alinear sus planes y programas a la Agenda 2030: Objetivos de Desarrollo Sostenible (ODS), mismos que establecen metas y recomendaciones en materia de reducción de riesgo de desastres, cambio climático y migraciones, donde se ha evidenciado que la Agenda solicita a los Estados que refuercen la cooperación internacional para garantizar una migración segura, ordenada y regular con respecto a los derechos humanos de los migrantes, destacando la vulnerabilidad de los migrantes, refugiados y desplazados internos. 


\section{Conclusiones}

La evidencia planteada en el desarrollo del artículo, confirma que a nivel internacional, existe un reconocimiento del fenómeno de refugiados ambientales como consecuencia del cambio climático, así lo señala el Foro Económico Mundial en su reporte titulado Informe de riesgos mundiales 2018, donde se enfatiza que el escenario de riesgos globales está dominado por los problemas ambientales derivados del cambio climático, principalmente por los fenómenos meteorológicos extremos y la inadecuada mitigación a los efectos del cambio climático, y la lenta adaptación de la ciudadanía.

En ese tenor, el Estado Mexicano aún tiene un largo camino que recorrer sobre este tema, porque aún su marco institucional se encuentra en desarrollo, ya que, si bien forma parte de la Iniciativa Nansen, ${ }^{3}$ aún no se cuenta con ningún instrumento jurídico que incluya la figura de refugiado ambiental, así como tampoco las organizaciones gubernamentales llámense Instituto Nacional Migración ni la Comisión Mexicana de Ayuda para Refugiados están preparados para atender a esta población que va en aumento, lo cual demuestra que no hay una correspondencia con acciones puntuales a nivel institucional.

En virtud de lo anterior, concluimos que es necesario el fortalecimiento de las instituciones gubernamentales, para estar preparados con protocolos de prevención y actuación necesarias para enfrentar el fenómeno de los refugiados ambientales, ya que hoy día nos enfrentamos a un panorama donde los factores ambientales deben de incluirse en las políticas y normas ambientales, migratorias y de derechos humanos. La clave es comprometer y corresponsabilizar a los diversos actores en la gestión ambiental y migratoria.

\section{Fuentes de consulta}

Alto Comisionado de las Naciones Unidas para los Refugiados (1993). The State of the World's Refugees: The Challenge of Protection, Ginebra. Recuperado de: http://www.unhcr.org/publications/sowr/4a4c6da96/state-worlds-refugees-1993challenge-protection.html

El-Hinnawi, E. (1985). Environmental Refugees, en United Nation Environmental Programme (UNEP), Nairobi, p. 41.

Escobar, A. (2007). La invención del Tercer Mundo Construcción y reconstrucción del desarrollo (capítulos I y II), primera edición, Fundación Editorial el perro y la rana. Gobierno Bolivariano de Venezuela. Venezuela, pp.424.

Felipe, B. (2018). Migraciones climáticas: una aproximación al panorama actual, Ecodes tiempo de actuar, España.

Hildyard, N. (2007). "La extracción de combustibles fósiles como generadora de refugiados ambientales”, Ecología Política 33, pp.37- 50.

\footnotetext{
${ }^{3}$ La Agenda Nansen enfatiza el rol de las organizaciones regionales y subregionales y sus mecanismos de protección de los derechos humanos, de reducción de riesgos de desastre, de estrategias de adaptación al cambio climático, de mercados comunes y de estrategias de libre circulación de personas.
} 
North, D. (2014). Instituciones, cambio institucional y desempeño económico, Cuarta reimpresión, Fondo de Cultura Económica, México.

Nansen Initiative (2015). The Nansen Initiative. Disasters and Cross-border Displacement, 2015, Recuperado de https://www.nanseninitiative.org/

OCDE/CAF/CEPAL (2018). Perspectivas económicas de América Latina 2018: Repensando las instituciones para el desarrollo. Editions OCDE, París. Disponible en: http://dx.doi.org/10.1787/leo-2018-es

Pires, E. (2016). Migración y cambio climático en la Agenda Global Pos 2015 en :Organización de las Naciones Unidas para la Educación, la Ciencia y la Cultura (2016). El cambio climático y u impacto en el goce de los derechos humanos, Seminarios Internacionales Pre COP22, Ediciones SAIJ, Buenos Aires.

Powell, W. y Dimmagio P. (Coord.) (1999). El nuevo institucionalismo en el análisis organizacional, Fondo de Cultura Económica, México, 580pp.

World Economic Forum (2018). Informe de riesgos mundiales 2018, 13.aedición, Ginebra; Suiza, 2018, disponible en: https://www.mmc.com/content/dam/mmc-web/GlobalRisk-Center/Files/the-global-risks-report-2018-es.pdf

Yamamoto, L. (2019). La migración ambiental en la Agenda 2030 en los países de Sudamerica: Argentina, Bolivia y Perú en: Migraciones en las Américas, Colegio de México, México, 443 pp.

\section{Legisgrafía}

Constitución Política de los Estados Unidos Mexicanos. Recuperado de: http://www.diputados.gob.mx/LeyesBiblio/pdf/1_270818.pdf

Convención sobre el Estatuto de los Refugiados, disponible en: https://www.acnur.org/5b0766944.pdf

Convención Marco de las Naciones Unidas sobre el Cambio Climático. Recuperado de: https://unfccc.int/resource/docs/convkp/convsp.pdf

Ley de Extranjería. Finlandia, 2004. Recuperado de: http://www.finlex.fi/en/laki/kaannokset/2004/en20040301.pdf

Ley de Extranjería, Suecia, 2005. Recuperado de: http://cort.as/-F0Ge

Ley sobre Refugiados, protección complementaria y Asilo politico. Recuperado de: http://www.diputados.gob.mx/LeyesBiblio/pdf/LRPCAP_301014.pdf

Ley de Migración. Recuperado de: http://www.diputados.gob.mx/LeyesBiblio/pdf/LMigra_120718.pdf

Ley General de Cambio Climático. Recuperado de: http://www.diputados.gob.mx/LeyesBiblio/pdf/LGCC_130718.pdf

Pacto Internacional de Derechos Civiles y Políticos. Recuperado de: https://www.ohchr.org/sp/professionalinterest/pages/ccpr.aspx

Pacto Internacional de Derechos Económicos, Sociales y Culturales. Recuperado de: https://www.ohchr.org/sp/professionalinterest/pages/cescr.aspx 